\title{
CARACTERIZACÃO DO RESÍDUO PROVENIENTE DA LIMPEZA DO FUNDO DO "LAGO AZUL", MUNICÍPIO DE RIO CLARO, SP, BRASIL
}

\section{WASTE CARACTERIZATION OF THE SLUDGE DUG FROM THE BOTTON OF "LAGO AZUL", RIO CLARO CITY, SP, BRASIL}

\section{Kataoka, A. N. ${ }^{1}$; Guerra, R. C. ${ }^{2}$ \& Angelis, D. F.}

Universidade Estadual Paulista - UNESP, Campus de Rio Claro - Av. 24 A, 1515 CEP 13506-720 Rio Claro, SP, Brasil

1 apagk@rc.unesp.com ; ${ }^{2}$ rcguerra@yahoo.com.br

\section{RESUMO}

A geração e a disposição final de resíduos produzidos pela atividade antrópica vem se tornando uma preocupação constante em vista dos efeitos negativos proporcionados ao meio ambiente quando estes são dispostos de maneira inadequada. Um dos principais aspectos a serem abordados quanto a disposição final destes resíduos esta relacionado a sua classificação. A norma NBR 10.004. "Resíduos Sólidos Classificação", classifica-os quanto sua fonte ou origem e quanto ao seu grau de periculosidade frente a determinados padrões de qualidade ambiental e de saúde pública. O objetivo deste estudo foi caracterizar o lodo retirado do fundo de um lago "Lago Azul", localizado na cidade de Rio Claro-SP, tendo em vista a destinação adequada deste resíduo. Os ensaios de Lixiviação, Solubilização e Biodegradação foram realizados de acordo com as normas ABNT. As análises da lixiviação e solubilização do resíduo demonstraram que este enquadra-se dentro dos limites estabelecidos nas respectivas normas técnicas, recebendo a classificação de resíduo inerte (classe-III). A biodegradabilidade do resíduo foi determinada através da aplicação de $0,30,50,70,100$ $\%$ do resíduo em um solo coletado no Aterro Sanitário de Rio Claro. A evolução do $\mathrm{CO}_{2}$ foi acompanhada pelo método respirométrico de Bartha durante 55 dias. Cada tratamento foi realizado em quadruplicata. Após o período inicial de 55 dias adicionou-se ácido 
glutâmico e chorume, também coletado no Aterro Sanitário, a cada dois frascos dos tratamentos realizados. Os resultados indicam baixa biodegradabilidade do resíduo, sendo que a máxima eficiência de biodegradação obtida foi de $11,6 \%$ no tratamento $100 \%$ resíduo, após a adição de chorume.

Palavras-chave: Resíduo Sólido; Lixiviação; Solubilização; Biodegradação

\section{ABSTRACT}

The generation and final disposal of wastes produced by the human activities are becoming a major concern, related with negative effects over the environment when its disposal occurs in inappropriate ways. One of the main aspects to considerate about the final disposal of wastes is related with its classification. The norm NBR 10.004 "Solid Wastes - Classification", classify them considering its origin and degree of environment hazard based on standards of environment quality and public health. The objective of this research was to characterize the sludge dug from the bottom of Lago Azul, intending its adequate destination. The tests of Leaching and Solubilization and Biodegradation wore realized following the respective technical norms. The analysis of Leaching and Solubilization tests showed that these waste fits in the parameters established by the respective technical norms, so being classified as an inert waste. The biodegradability was determined through the application of $0,30,50,70,100 \%$ of the waste over a soil collected in the sanitary landfill of Rio Claro City. The production of $\mathrm{CO}_{2}$ was monitored though Bartha's respirometric methods for 55 days. Each treatment was built in four repetitions. After the initial period of 55 days glutamic acid and leachate from Rio Claro's sanitary landfill wore added at two flasks of each performed treatment. The results indicate low biodegradability of the waste, being the achieved maximum biodegradation efficiency of $11,6 \%$ by the treatment containing $100 \%$ of waste, after the addiction of leachate.

Key-words: Solid Waste; Leaching; Solubilization; Biodegradation.

\section{INTRODUÇÃO}

A geração e disposição final de resíduos produzidos pela atividade antrópica, vem se tornando uma preocupação constante em vista dos efeitos negativos proporcionados ao meio ambiente, quando estes são dispostos de maneira inadequada.

A quantidade de resíduos produzida por uma comunidade está relacionada a fatores culturais, condições sócio-econômicas, hábitos e costumes da população, poder aquisitivo, fatores climáticos, características de sexo e idade dos grupos populacionais, 
leis e regulamentações específicas (Bidone; Povinelli, 1999).

A crescente demanda da sociedade pela manutenção e melhoria das condições ambientais tem exigido das autoridades e empresas públicas e privadas, atividades capazes de compatibilizar o desenvolvimento às limitações da exploração dos recursos naturais. Esta preocupação com a qualidade ambiental tem suscitado no desenvolvimento de políticas e medidas legislativas que funcionam como diretrizes para o estabelecimento de critérios e padrões sobre contaminação (Bettiol; Camargo, 2001)

De acordo com a norma técnica NBR 10.004 "Resíduos Sólidos Classificação" (ABNT, 1987a), resíduos sólidos são todos os resíduos, no estado sólido ou semi-sólido, que resultam da atividade da comunidade podendo ser de origem industrial, doméstica, hospitalar, comercial, de serviços ou agrícolas. Incluem-se dentro desta definição os lodos provenientes das ETAs (Estações de tratamento de água) e ETEs (Estações de tratamento de esgotos), resíduos gerados em equipamentos e instalações de controle de poluição e líquidos que não podem ser lançados na rede pública de esgoto.

Um dos principais aspectos a serem abordados quanto à disposição final destes resíduos está relacionado a sua classificação. A norma técnica NBR 10.004 (ABNT, 1987a), classifica-os quanto à sua fonte ou origem e quanto ao seu grau de periculosidade frente a determinados padrões de qualidade ambiental e de saúde pública.

$\mathrm{Na}$ impossibilidade do enquadramento do resíduo nos critérios adotados pela norma, esta estabelece a necessidade de realizações de ensaios tecnológicos para avaliar as concentrações dos elementos que conferem periculosidade, de acordo com as listagems apresentadas pela própria norma.

Portanto, a NBR 10.004 (ABNT, 1987a) está vinculada a três outras normas, a saber: NBR 10.007 "Amostragem de resíduos - Procedimentos", que estabelece os critérios de coleta e seleção das amostras (ABNT, 1987d); NBR 10.005 "Lixiviação de resíduos - Procedimento", que consiste na separação de certas substâncias contida no resíduo por meio de lavagem ou percolação (ABNT,1987b) e NBR 10.006 "Solubilização de resíduos - Procedimento" que visa a solubilização da amostra em água e avaliação da concentração dos elementos e materiais presente no extrato (ABNT, 1987c).

Deste modo, a partir dos ensaios e critérios definidos, os resíduos sólidos podem ser classificados, enquadrando-se nas seguintes categorias: Classe I - resíduos perigosos; Classe II - resíduos não inertes e Classe III - resíduos inertes.

Hoje já se conhecem várias técnicas para o tratamento de lodos e de resíduos sólidos, sendo que, estas devem ser utilizadas sempre que houver risco ao homem ou ao meio ambiente. As principais técnicas de tratamento de resíduos sólidos industriais são os aterros industriais, "landfarming", encapsulamento e incineração (CASTRO NETO et al., 1985). 
A disposição no solo pode constituir-se em excelente forma de tratamento, desde que se respeite a capacidade natural do meio e dos microrganismos decompositores presentes (Campos, 1994).

Os aterros convencionais podem ser utilizados para a disposição conjunta de resíduos orgânicos e resíduos sólidos não perigosos. Apesar de representar uma medida interessante do ponto de vista econômico, principalmente para os países em desenvolvimento, este procedimento deve ser realizado com cautela a fim de se evitar alterações significativas dos líquidos percolados dos aterros.

O principal problema a ser enfrentado com o uso da codisposição ou disposição conjunta é a determinação da fração ideal de resíduo a ser adicionada aos resíduos orgânicos de tal forma que se continue garantindo o bom desempenho dos aterros.

Para Castro Neto et al. (1985) este procedimento somente deve ser adotado com a garantia de que as reações físicas, químicas e biológicas que ocorrem no lixo doméstico ocorram também no resíduo "codisposto". Esta garantia é necessária para que se assegure a ocorrência da atenuação deste resíduo, que ocorre mediante fenômenos de diluição, dispersão, adsorção do poluente, degradação dos compostos orgânicos e a precipitação dos cátions.

Os aterros são ambientes ecologicamente heterogêneos, portanto a presença de um resíduo industrial no meio poderá promover a inibição de linhagens sensíveis ou o crescimento de microrganismos capazes de utilizar seus compostos (Tibbles; Baecker, 1989 apud Souza, 2000).

O ensaio de respirômetria tem sido utilizado como indicador da atividade biológica constituindo-se importante ferramenta de avaliação do potencial de biodegradação dos resíduos dispostos no solo. Este ensaio permite estimar o tempo de estabilização do resíduo quando disposto no solo, determinar a taxa de aplicação adequada bem como verificar a possível inibição da população microbiana por agentes tóxicos (Siviero, 1999).

As técnicas de avaliação da respirômetria, utilizadas em pesquisas relacionadas à degradação de lodos de esgotos no solo, apresentam resultados satisfatórios quanto a estabilização destes resíduos (Snyman et al., 1998; Nuvolari, 1996).

Portanto, dentro deste contexto, percebe-se a necessidade do conhecimento prévio das características do resíduo industrial que se deseja codispor e do desenvolvimento de estudos no sentido de determinar a possível influência deste no meio. Neste sentido, este trabalho teve como objetivo a caracterização do lodo retirado do fundo de um lago no município de Rio Claro-SP, visando sua destinação final. 


\section{MATERIAL E MÉTODOS}

\section{Amostragem do solo e resíduo:}

O solo utilizado no ensaio de respirometria foi coletado no aterro sanitário de Rio Claro segundo a Norma Técnica L6.245 - "Solos. Coleta e preparação de amostras Procedimentos" (CETESB, 1984).

O resíduo foi retirado do fundo de um lago situado na cidade de Rio Claro. Este localiza-se em um parque da cidade, utilizado pela população local para a prática de atividades físicas e lazer. O lago teve sua construção após a canalização de um córrego (Córrego da Servidão) que hoje encontra-se sob uma movimentada avenida. Este lago recebe a água das nascentes do córrego e de galerias de águas pluviais, funcionando como um regulador do fluxo de água do córrego, um tributário do rio Corumbataí. Patos e outros animais vivem neste ambiente, contribuindo com o aporte de matéria orgânica. A

limpeza do fundo do lago foi realizada por dragas, que totalizaram a retirada de $31.600 \mathrm{~m}^{3}$ de lodo, sendo então este resíduo levado por caminhões basculantes até uma área onde foi realizada a retirada da água por evaporação. Este resíduo seco foi então amontoado e deixado ao ar livre para posterior disposição final.

\section{Ensaio de solubilização do resíduo:}

A solubilização do resíduo foi efetuada conforme Norma NBR 10.006 (ABNT, 1987c). O solubilizado foi analisado quanto aos seguintes parâmetros: $\mathrm{pH}$, condutividade elétrica, resíduos voláteis, resíduos fixos, demanda química de oxigênio (DQO), metais pesados e toxicidade.

\section{Ensaio de lixiviação do resíduo:}

A lixiviação do resíduo foi efetuada conforme Norma NBR 10.005 (ABNT, 1987b). O lixiviado foi analisado quanto aos seguintes parâmetros: $\mathrm{pH}$, condutividade elétrica, sólidos suspensos, resíduos voláteis, resíduos fixos, demanda química de oxigênio (DQO) e metais pesados.

Neste ensaio, a mistura "água desionizada e resíduo", foi mantida em agitação constante durante o período de 28 horas. Ao final do ensaio, após processo de filtração com membrana de $0,45 \mathrm{~m} \mathrm{~m}$, obteve-se um volume de $1,960 \mathrm{~L}$ de extrato lixiviado, utilizando $5,2 \mathrm{~mL}$ de ácido acético $0,5 \mathrm{~N}$ para a correção e estabilização do $\mathrm{pH}$.

\section{Ensaio de biodegradação do resíduo:}

O ensaio de biodegradação do resíduo foi realizado segundo Norma Técnica 
L6.350 - "Solos - Determinação da biodegradação de resíduos - Método respirométrico de Bartha" (CETESB, 1990). O respirômetro de Bartha é um sistema fechado, constituído de duas câmaras interligadas, onde ocorrem a biodegradação do resíduo e a remoção do $\mathrm{CO}_{2}$ produzido no processo (BARTHA; PRAMER, 1965).

O teor de umidade do solo utilizado no ensaio foi corrigido para $70 \%$ de sua capacidade de campo. Este solo foi misturado ao resíduo de acordo com as seguintes taxas de aplicação: $0,30,50,70$ e $100 \%$ de resíduo.

Após a homogeneização $50 \mathrm{~g}$ da mistura foi adicionada aos respirômetros. Cada tratamento foi realizado em quadruplicata. Os respirômetros foram incubados a $20^{\circ}$ $\mathrm{C}$ por 13 dias e a $25^{\circ} \mathrm{C}$ pelo período restante.

Após 55 dias de incubação adicionou-se $10 \mathrm{~mL}$ de chorume, proveniente do Aterro Sanitário de Rio Claro-SP, em dois respirômetros de cada tratamento e 1,5 mg de ácido glutâmico aos outros dois respirômetros de cada tratamento.

\section{RESULTADOS E DISCUSSÃO}

\section{Análises Físicas e Químicas do Solo e Resíduo}

O solo utilizado no ensaio de respirometria foi classificado como limo arenoso, sub classe arenoso, de acordo com a análise granulométrica apresentada na Tabela 1.

Tabela 1 - Análise granulométrica do solo do Aterro Sanitário do Município de Rio Claro

\begin{tabular}{|c|c|c|c|c|c|c|}
\hline \multicolumn{5}{|c|}{ Composição Granulométrica (\%) } & \multirow{2}{*}{\multicolumn{2}{|c|}{$\begin{array}{l}\text { Densidades } \\
\left(\mathrm{g} / \mathrm{cm}^{3}\right)\end{array}$}} \\
\hline \multicolumn{5}{|c|}{ Areias } & & \\
\hline Grossa & Fina & Argila & Limo & Cascalho & Aparente & Real \\
\hline 40,2 & 38,6 & 11,2 & 10,0 & 0,0 & 1,19 & 2,63 \\
\hline
\end{tabular}

Na tabela 2 estão inseridos os resultados das análises químicas do solo do Aterro Sanitário utilizado nos ensaios de respirometria e do lodo retirado do fundo do Lago Azul. 
Verificou-se que o teor de matéria orgânica presente no resíduo é elevado. As outras substâncias analisadas encontram-se dentro dos valores naturais encontrados para o Estado de São Paulo com exceção do chumbo, onde o limite natural máximo é de $23 \mathrm{mg} / \mathrm{Kg}$. Entretanto sua concentração não atinge o valor de intervenção proposto pela CETESB (Companhia de Tecnologia de Saneamento Ambiental) em nenhuma de suas classificações de uso do solo (Ârea de proteção máxima, Agrícola, Residencial e Industrial).

O resíduo apresentou ainda altos valores de CTC. A CTC de um solo representa a capacidade de retenção de cátions, ou seja, a quantidade de cargas ou de cátions retidos, por unidade de peso ou volume de solo. Em geral, as partículas de argila são responsáveis por esta capacidade, por possuírem cargas negativas que são equilibradas por cátions trocáveis que aderem às superfícies e as extremidades das partículas.

A matéria orgânica encontrada nos solos também contribui para a adsorção de cátions, assim como de grande variedade de compostos orgânicos. A fração dos ácidos húmicos é carregada negativamente devido ao elevado conteúdo de grupos funcionais ionizáveis, podendo, deste modo, apresentar grande capacidade de troca.

Deste modo a elevada capacidade de troca catiônica apresentada pela análise do resíduo indica que este encontra-se pouco disponível para a atuação dos microrganismos.

Tabela 2 - Teores, expressos em $\mathrm{mg} / \mathrm{dm}^{3}$, de parâmetros químicos em amostras de solo do aterro sanitário e do lodo do fundo do Lago Azul. Município de Rio Claro-SP.

\begin{tabular}{||l||c||c||}
\hline \multicolumn{1}{|c||}{ Parâmetros } & Solo & Lodo \\
\hline \hline Mat. orgânica & 2000 & 24000 \\
\hline \hline pH & 4,5 & 5,2 \\
\hline \hline CTC & 348,8 & 1269,5 \\
\hline \hline Fósforo $(\mathrm{P})$ & 3,0 & 14,0 \\
\hline \hline Potássio $(\mathrm{K})$ & 7,8 & 19,5 \\
\hline \hline Cálcio $(\mathrm{Ca})$ & 200,0 & 1000 \\
\hline \hline
\end{tabular}




\begin{tabular}{|c|c|c|}
\hline Magnésio (Mg) & 73,0 & 219,0 \\
\hline Sódio (Na) & 1,0 & 9,0 \\
\hline Enxofre (S) & 12,0 & 22,0 \\
\hline Alumínio (Al) & 54,0 & $<0,01$ \\
\hline Ferro $(\mathrm{Fe})$ & 9,0 & 139,0 \\
\hline Manganês (Mn) & 0,8 & 6,0 \\
\hline Cobre $(\mathrm{Cu})$ & 0,3 & 3,5 \\
\hline Zinco $(\mathrm{Zn})$ & 0,4 & 13,8 \\
\hline Boro (Bo) & 0,24 & 0,28 \\
\hline Cobalto (Co) & 0,05 & $*$ \\
\hline Molibdênio (Mo) & 0,04 & $*$ \\
\hline Silício (Si) & $*$ & 42,5 \\
\hline Estrôncio (Sr) & $*$ & $<0,01$ \\
\hline Cromo (Cr) & $*$ & $<0,01$ \\
\hline Chumbo $(\mathrm{Pb})$ & $*$ & 53,47 \\
\hline Cádmio (Cd) & $*$ & 0,039 \\
\hline
\end{tabular}

*não determinado.

\section{Ensaio de lixiviação e solubilização do resíduo}

Tanto o extrato lixiviado como o solubilizado foram analisados frente a diversos parâmetros, apresentados na Tabela 3. A avaliação da toxicidade do extrato solubilizado, produto do ensaio de solubilização, utilizando o método de avaliação com o microcrustáceo Daphnia similis não demonstrou toxicidade ao organismo teste. Os resultados das análises fisico-químicas encontram-se de acordo com as respectivas Normas Técnicas de controle ambiental, não excedendo aos limites máximos estabelecidos, sendo portanto este resíduo classificado Resíduo Classe III - Inerte.

Tabela 3 - Resultados das análises físico-químicas do lixiviado e solubilizado, do lodo 
do fundo do Lago Azul. Município de Rio Claro-SP. e concentrações máximas estabelecidas pelas respectivas normas técnicas

\begin{tabular}{|c|c|c|c|c|c|}
\hline Parâmetros & Solubilizado & $\mathrm{L} \mathrm{M}^{1}$ & Lixiviado & $\mathrm{L} \mathrm{M}^{1}$ & Unidade \\
\hline \multirow{2}{*}{$\mathrm{pH}$} & \multirow{2}{*}{6,49} & & $\begin{array}{c}\text { Inicial } \\
6,70\end{array}$ & & \\
\hline & & & Final 5,60 & & \\
\hline Condutividade & 95,65 & & 131,0 & & $\mathrm{~m} \mathrm{~S} / \mathrm{cm}$ \\
\hline DQO. & 11,34 & & 30,23 & & $\mathrm{mgO}_{2} / \mathrm{L}$ \\
\hline Toxicidade & Não tóxico ${ }^{2}$ & & - & & \\
\hline $\begin{array}{l}\text { Resíduos } \\
\text { Voláteis }\end{array}$ & 0,0217 & & 0,0664 & & $\mathrm{~g} / \mathrm{L}$ \\
\hline $\begin{array}{l}\text { Resíduos } \\
\text { Fixos }\end{array}$ & 0,0638 & & 0,0618 & & $\mathrm{~g} / \mathrm{L}$ \\
\hline $\begin{array}{c}\text { Sólidos } \\
\text { Suspensos }\end{array}$ & - & & 3,36 & & $\%$ \\
\hline Sódio $(\mathrm{Na})$ & 2,0 & 200 & 2,9 & $*$ & $\mathrm{mg} / \mathrm{L}$ \\
\hline Potássio (K) & 1,3 & $*$ & 1,6 & $*$ & $\mathrm{mg} / \mathrm{L}$ \\
\hline Silício (Si) & 3,75 & $*$ & 2,5 & $*$ & $\mathrm{mg} / \mathrm{L}$ \\
\hline Cálcio $(\mathrm{Ca})$ & 7,3 & $*$ & 14,9 & $*$ & $\mathrm{mg} / \mathrm{L}$ \\
\hline Estrôncio $(\mathrm{Sr})$ & 0,02 & * & 0,05 & $*$ & $\mathrm{mg} / \mathrm{L}$ \\
\hline $\begin{array}{l}\text { Magnésio } \\
(\mathrm{Mg})\end{array}$ & 3,0 & * & 4,4 & * & $\mathrm{mg} / \mathrm{L}$ \\
\hline Chumbo $(\mathrm{Pb})$ & $<0,025$ & 0,05 & $<0,025$ & 5,0 & $\mathrm{mg} / \mathrm{L}$ \\
\hline Ferro (Fe) & 0,13 & 0,3 & 0,11 & $*$ & $\mathrm{mg} / \mathrm{L}$ \\
\hline $\begin{array}{c}\text { Manganês } \\
(\mathrm{Mn})\end{array}$ & 0,04 & 0,1 & 0,16 & * & $\mathrm{mg} / \mathrm{L}$ \\
\hline Cromo $(\mathrm{Cr})$ & $<0,01$ & 0,05 & $<0,01$ & 5,0 & $\mathrm{mg} / \mathrm{L}$ \\
\hline Fósforo (P) & $<0,1$ & * & $<0,1$ & * & $\mathrm{mg} / \mathrm{L}$ \\
\hline Alumínio (Al) & 0,18 & 0,2 & $<0,05$ & * & $\mathrm{mg} / \mathrm{L}$ \\
\hline
\end{tabular}




\begin{tabular}{||c||c||c||c||c||c||} 
Zinco $(\mathrm{Zn})$ & 0,065 & 5,0 & 0,27 & $*$ & $\mathrm{mg} / \mathrm{L}$ \\
\hline \hline Cobre $(\mathrm{Cu})$ & $<0,01$ & 1,0 & $<0,01$ & $*$ & $\mathrm{mg} / \mathrm{L}$ \\
\hline \hline Bário $(\mathrm{Ba})$ & 0,015 & 1,0 & 0,04 & 100 & $\mathrm{mg} / \mathrm{L}$ \\
\hline \hline Cobalto $(\mathrm{Co})$ & $<0,01$ & $*$ & $<0,01$ & $*$ & $\mathrm{mg} / \mathrm{L}$ \\
\hline \hline Níquel $(\mathrm{Ni})$ & $<0,01$ & $*$ & $<0,01$ & $*$ & $\mathrm{mg} / \mathrm{L}$ \\
\hline \hline Cádmio $(\mathrm{Cd})$ & $<0,005$ & 0,005 & 0,005 & 0,5 & $\mathrm{mg} / \mathrm{L}$ \\
\hline
\end{tabular}

\section{Limite Máximo}

- parâmetro não requerido para execução da respectiva análise

* parâmetro não considerado pela NBR 10004 (Anexo G e H, Listagem 7 e 8)

2 determinada através do teste com Daphnia similis.

\section{Ensaio de biodegradação}

O ensaio de biodegradação do resíduo em sua $1^{\circ}$ fase (55 dias iniciais) apresentou lenta produção de $\mathrm{CO}_{2}$. A aplicação de diferentes concentrações de resíduo ao solo acarretou gradual aumento na produção de $\mathrm{CO}_{2}$, como demonstrado na Figura 1.

A aplicação de $100 \%$ de resíduo foi responsável pela maior taxa de produção de $\mathrm{CO}_{2}$, representando um incremento de $277 \%$ em sua produção com relação ao solo controle. As taxas de aplicação do resíduo de 30\%, 50\% e 70\% representaram respectivamente aumento de $26 \%, 43 \%$ e $137 \%$ na produção de $\mathrm{CO}_{2}$.

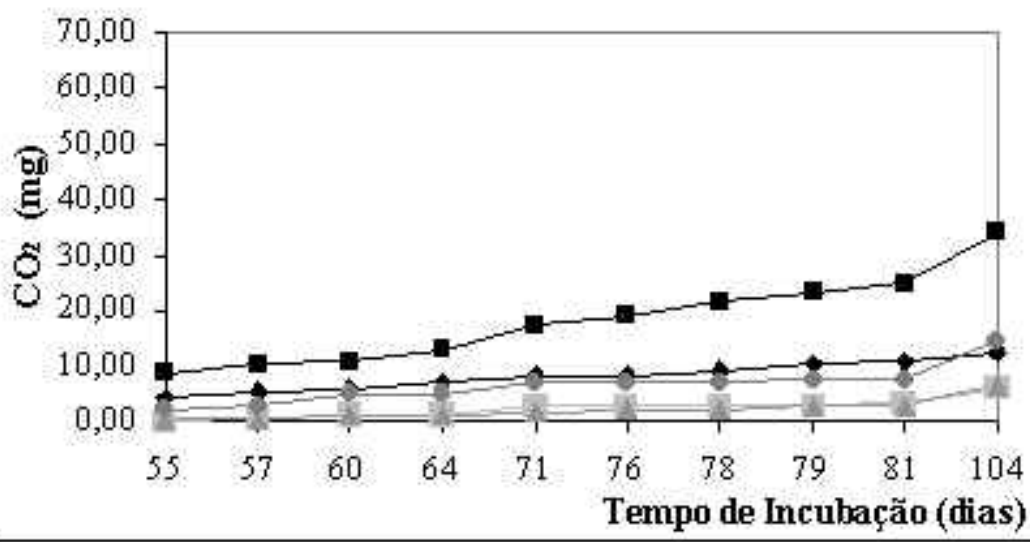


Figura 1 - Produção de $\mathrm{CO}_{2}$ acumulada devido a biodegradação do resíduo durante 55 dias.

Em virtude da lenta biodegradação do resíduo, decidiu-se adicionar a dois respirômetros de cada tratamento $10 \mathrm{~mL}$ de chorume e aos outros dois $1,5 \mathrm{~mL}$ de ácido glutâmico (Figuras 2 e 3), com a finalidade de proporcionar, respectivamente, o enriquecimento da população microbiana e uma fonte adicional de carbono ao sistema.

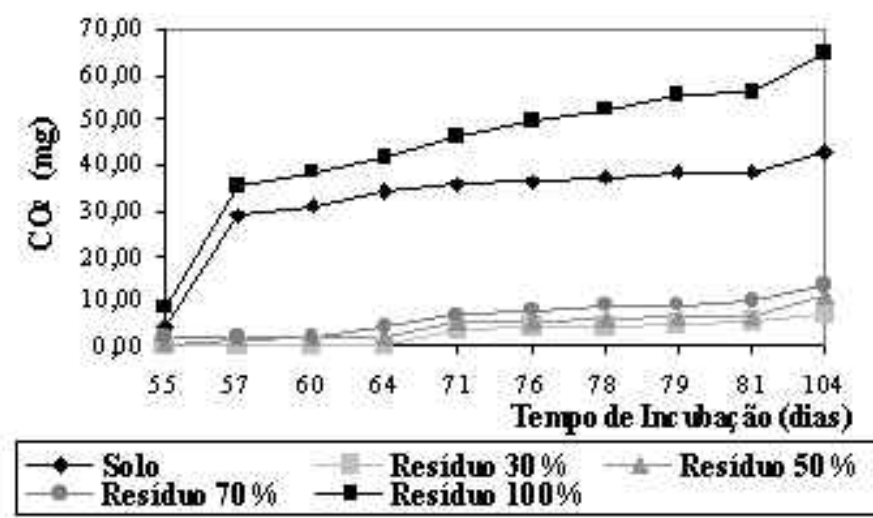

Figura 2 - Produção de $\mathrm{CO}_{2}$ acumulada devido a biodegradação do resíduo após adição de chorume.

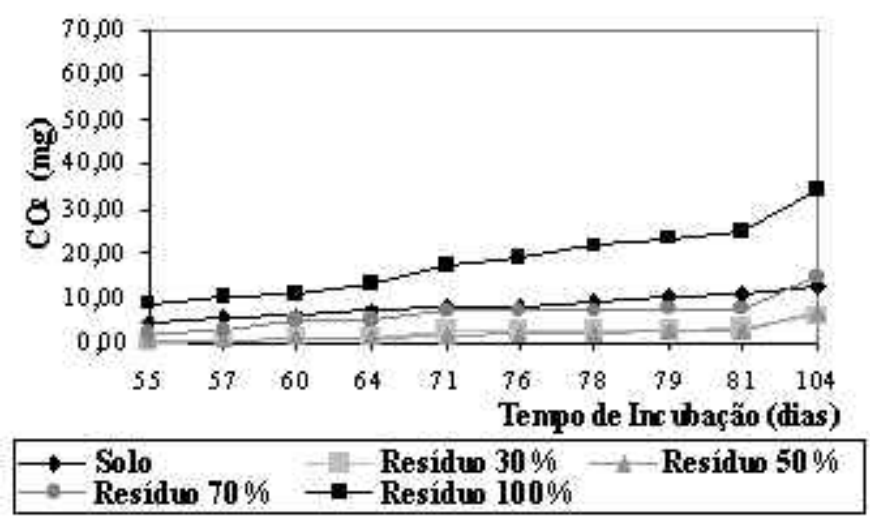

Figura 3 - Produção de $\mathrm{CO}_{2}$ acumulada devido a biodegradação do resíduo após adição de acido glutâmico.

Nesta $2^{\circ}$ fase, a biodegradação do resíduo foi acompanhada por mais 49 dias, totalizando um período de 104 dias de ensaio. Observando-se a Figura 2 pode-se notar uma elevação inicial na produção de $\mathrm{CO}_{2}$ nos tratamentos controle e $100 \%$, isto 
provavelmente deu-se em virtude da biodegradação que estava ocorrendo na matéria orgânica presente no chorume adicionado. Esta elevação não é observada nos demais tratamentos $(30 \%, 50 \%$ e $70 \%)$, pois destes descontou-se a taxa de produção de $\mathrm{CO}_{2}$ do tratamento controle, para obter exclusivamente $\mathrm{o} \mathrm{CO}_{2}$ produzido pela biodegradação do resíduo; no tratamento utilizando $100 \%$ do resíduo, por este conter apenas resíduo, esta subtração não ocorreu.

Desta forma, entre os tratamentos utilizando chorume e ácido glutâmico pode-se notar pequena diferença na taxa de produção de $\mathrm{CO}_{2}$, não sendo notado incremento satisfatório na biodegradação do resíduo.

Os resultados obtidos na tabela 4 demonstram que a maior eficiência da biodegradação do resíduo foi alcançada com o tratamento contendo $100 \%$ de resíduo e adição de chorume. Esta constatação reforça o resultado obtido através do teste de toxicidade, demonstrando que este resíduo não apresentou efeito inibitório sobre os microrganismos presentes. Entretanto sua biodegradação ocorreu lentamente, pois a matéria facilmente biodegradável foi consumida no período em que este encontrava-se depositado no fundo do lago. Desta forma, durante os 104 dias do ensaio de respirômetria verificou-se que a parte orgânica residual continuava sendo biodegradada, porém em taxas lentas, de tal forma que no período estudado não atingiu-se a eficiência de 30\% como recomendado pela Norma Técnica L6.350 (Cetesb, 1990).

Tabela 4 - Valores de eficiência da biodegradação do resíduo nos 55 dias iniciais e após adição de chorume e ácido glutâmico.

\begin{tabular}{lccc}
\hline \multirow{2}{*}{ Tratamento } & \multicolumn{3}{c}{ Eficiência da Biodegradação (\%) } \\
\cline { 2 - 4 } & 55 dias Iniciais & Chorume & Ac. Glutâmico \\
\hline Solo & 2,5 & 10,5 & 3,1 \\
Residuo 30\% & 0,62 & 1,58 & 1,36 \\
Residuo 50\% & 0,9 & 2,22 & 1,36 \\
Residuo 70\% & 2,5 & 2,34 & 2,61 \\
Residuo $100 \%$ & 4,93 & 11,65 & 6,14 \\
\hline
\end{tabular}


As análises referentes ao resíduo indicam que este não oferece periculosidade ou riscos de contaminação ambiental, como conseqüência de sua disposição no solo.

Sendo este um resíduo classificado como inerte ele poderá ser utilizado para codisposição em aterro sanitário.

A ausência de toxicidade, evidenciada pelo ensaio de toxicidade do extrato solubilizado e pelo ensaio de respirômetria, em que a atividade microbiana não sofreu inibição mesmo nas maiores concentrações de aplicação do resíduo, indicam que este não oferece prejuízos a atividade de biodegradação dos microrganismos presentes no aterro sanitário.

\section{REFERÊNCIAS}

Associação Brasileira de Normas Técnicas. NBR - 10.004: Resíduos Sólidos: classificação. Rio de Janeiro, 1987(a), 33p.

Associação Brasileira de Normas Técnicas. NBR - 10.005: Lixiviação de Resíduos. Rio de Janeiro, 1987(b), 10p.

Associação Brasileira de Normas Técnicas. NBR - 10.006: Solubilização de Resíduos. Rio de Janeiro, 1987(c), 2p.

Associação Brasileira de Normas Técnicas. NBR - 10.007: Amostragem de Resíduos. Rio de Janeiro, 1987(d), 33p.

Bartha, R.; Pramer, D. Features of flask and method for measurement the persistence and biological effects of pesticides in soil. Soil Science, v.100, 1965. p. 68-70.

Bettiol, W; Camargo, O. A. Reciclagem de Lodo de Esgoto na Agricultura. In: MELO, I. S. (Ed.). Workshop sobre Biodegradação, 2. Jaguariúna: Embrapa Meio Ambiente, 2001. p. 93-106.

Bidone, F.R.A; Povinelli, J. Conceitos básicos de resíduos sólidos. Publicação EESCUSP, São Carlos, 1999, 120p.

Campos, J. R. Alternativas para Tratamentos de Esgotos - Pré Tratamento de Águas para Abastecimento. Americana: Consórcio Intermunicipal das Bacias dos Rios Piracicaba e Capivari, 1994, 112p.

Castro Neto, P.P. et. al., Resíduos sólidos industriais. CETESB/ASCETESB. São Paulo. $1985,182 p$. 
COMPANHIA DE TECNOLOGIA DE SANEAMENTO AMBIENTAL. L6.245: Coleta e preparação de amostras: procedimentos. São Paulo, 1984.

Companhia de Tecnologia de Saneamento Ambiental. L6.350: Determinação da biodegradação de resíduos: método respirométrico de Bartha. São Paulo, 1990, 15p.

Nuvolari, A. Aplicação de lodo de esgotos municipais no solo: ensaios de respirometria para avaliar a estabilidade do lodo. 1996. 158f. Dissertação. (Mestrado em Recursos Hídricos e Saneamento)- UNICAMP, Faculdade De Engenharia Civil. Campinas.

Siviero, A. R. Avaliação da biodegradação em solo de resíduos sólidos de fundição areia fenólica - utilizando o método respirométrico. 1999. 78f. Tese (Doutorado em Ciências Biológicas)- UNESP, Instituto de Biociências. Rio Claro.

Snyman, H. G.; de Jong, J.M.; Aveling, T. A. S. The stabilization of sewage sludge applied to agricultural land and the effects on maize seedlings. Water Science and Technology, v.38, n.2, 1998, p. $87-95$.

Souza, A M.G.F. Aplicação de método respirométrico na avaliação do emprego de areia fenólica de fundição, juntamente com solo, na cobertura de aterro sanitário. 2000. 132f. Tese (Doutorado em Ciências Biológicas)- UNESP, Instituto de Biociências. Rio Claro. 